\section{AB0014 GENETIC MARKERS OF METHOTREXATE HEPATOTOXICITY IN PATIENTS WITH RHEUMATOID ARTHRITIS}

N. Martusevich ${ }^{1}$, E. Aksenova ${ }^{2}$, K. Gudkevich ${ }^{3} .{ }^{1}$ Belarusian State Medical University, Minsk, Belarus; ${ }^{2}$ The Institute of Genetics and Cytology, Minsk, Belarus; ${ }^{3}$ Minsk City Clinical Hospital No. 6, Minsk, Belarus

Background: Methotrexate (MT) is a first-line drug in the treatment of rheumatoid arthritis (RA). The effectiveness and tolerability of the use of MT largely determines the prognosis of the course of the disease, the speed of achieving remission The development of hepatotoxicity $(\mathrm{HT})$ is the most common adverse reaction, it is noted in $5-12.5 \%$ of cases and often requires the abolition of MT. In this regard, predicting the development of $\mathrm{HT}$ seems to be an important area of research. Objectives: to study genetic predictors of HT development in patients with RA using MT.

Methods: 44 patients with a reliable diagnosis of RA were included in study. All of the patients used MT at a dose of 15.0 (12.5-17.5) mg/week in combination with folic acid $3-5 \mathrm{mg} /$ day outside of MT. The average age was $46.7 \pm 12.3$ years; females- $81.8 \%(n=36)$; mail $18.2 \%(n=8)$. The duration of RA is $5.3 \pm 2.2$ months. All patients were divided into two groups: the first study group $(n=17)$ included patients with RA who developed a $\mathrm{HT}$ reaction to $\mathrm{MT}$, which required the abolition of MT; in the second- $(n=27)$ - comparison group - patients with good efficacy and tolerability of MT.

Genotypes for polymorphic alleles were analyzed in all patients: C677T (rs1801133) and A1298C (rs1801131) of the methylenetetrahydrofolate reductase gene (MTHFR); $347 \mathrm{C}>\mathrm{G}$ single-nucleotide polymorphism of the gene of aminoimidazole-carboxamidoriboside transformylase / inosine monophosphate cyclohydrolase (ATIC); c.80G> A locus of the SLC19A1 gene encoding the folate transporter membrane carrier protein.Groups were compared according to possible inheritance models: dominant, recessive, codominant. Statistical data processing was carried out using the SATISTICA 10.0 software package using descriptive and nonparametric statistics methods. Results: The frequency of occurrence of various mutations in genes that affect the metabolism of MT among patients with RA in the study and comparison groups are presented in table 1

Table 1. The frequency of occurrence of various mutations in genes that affect the metabolism of MT

\begin{tabular}{lcc}
\hline Genetic option & $\begin{array}{c}\text { Study group } \\
\Gamma \mathrm{T}+, \mathrm{n}=17\end{array}$ & $\begin{array}{c}\text { Comparison group } \\
\Gamma \mathrm{T}<<->>, \mathrm{n}=27\end{array}$ \\
\hline MTHFR-A1298C & & \\
CC & 5 & 6 \\
CA & 2 & 8 \\
AA & 10 & 13 \\
MTHFR -C677T & 7 & 9 \\
CC & 8 & 17 \\
CT & 2 & 1 \\
TT & & \\
347C>G ATIC & 9 & 6 \\
CC & 6 & 19 \\
GG & 2 & 2 \\
SLC19A1C80A>G & & \\
AA & 11 & 22 \\
AG & 6 & 4 \\
GG & 0 & 0 \\
\hline
\end{tabular}

$\Gamma T$ - hepatotoxicity

When analyzing inheritance models, it was found that differences in hepatotoxicity for comparing genotypes (MTHFR-A1298C, MTHFR-C677T, SLC19A1c80A> G) were not statistically significant. A statistically significant increase in the risk of hepatotoxicity was found for dominant $(2.18(1.06-4.47), \mathrm{x} 2=4.38, \mathrm{p}=0.03)$ and codominant $(0.42(0.19-0.92), x 2=5.23, p=0.02)$ models for the 347C> G ATIC gene. Conclusion: Thus, an increase in the risk of hepatotoxicity for the dominant and codominant models for the 347C>G ATIC gene allows recommending genotyping of the alleles of this gene before MT administration in order to reduce the risk of hepatotoxic reactions.

Disclosure of Interests: Natalia Martusevich Shareholder of: k, E. Aksenova: None declared, Katsiarina Gudkevich: None declared DOI: 10.1136/annrheumdis-2020-eular.6571

\section{AB0015 \\ IDENTIFICATION OF KEY GENES TO SUPPORT SYSTEMIC LUPUS ERYTHEMATOSUS, RHEUMATOID ARTHRITIS AND ANKYLOSING SPONDYLITIS DIAGNOSIS BY TRANSCRIPTOMIC APPROACH}

A. Mashayekhi Sardoo ${ }^{1}$, P. Leo ${ }^{2}$, M. Santos ${ }^{3}$, T. Costa', S. F. Almeida ${ }^{4}$, S. Maia', V. Benes ${ }^{5}$, M. Brown ${ }^{6}$, J. Branco ${ }^{1,7}$, F. Pimentel Dos Santos ${ }^{1,7} .{ }^{1}$ NOVA Medical School, Universidade NOVA de Lisboa, CEDOC, Lisbon, Portugal; ${ }^{2}$ Queensland
University of Technology, Institute of Health and Biomedical Innovation, Medical Engineering Research Facility, Chermside, Australia; ${ }^{3}$ Champalimaud Foundation, Lisboa, Portugal; ${ }^{4}$ Instituto de Medicina Molecular (IMM), Lisboa, Portugal; ${ }^{5}$ EMBL Heidelberg, Heidelberg, Germany; ${ }^{6}$ King's College London, National Institute for Health Research (NIHR) Guy's and St Thomas' Biomedical Research Centre (BRC), London, United Kingdom; ${ }^{7}$ Hospital Egas Moniz, Lisboa, Portugal

Background: Early diagnosis of inflammatory rheumatic diseases (IRD), as Systemic Lupus Erythematosus (SLE), Rheumatoid Arthritis (RA) and axial Spondyloarthritis (axSpA) represents in our days a major clinical challenge. Increasing evidence has determined that early diagnosis, prompt treatment initiation and early achievement of remission are the best predictors of long-term clinical, functional and radiographic outcomes. Therefore, identification of sensitive biomarkers to support an early diagnosis to enable early therapy is of utmost importance $[1,2]$ Objectives: This study aims to identify novel genes that may improve the current clinical diagnosis approach for early SLE, RA and axSpA.

Methods: A cross-sectional study was conducted on 44 participants, 12 with axSpA (according to ASAS criteria), 11 with RA (according to ACR/EULAR criteria for RA), 10 with SLE (according to ACR classification criteria for SLE) and 11 Healthy Controls $(\mathrm{HC})$, gender and age matched. Patients with co-occurrence of other IRD or having received biological therapies were excluded. Peripheral blood samples were collected into PAXgene tubes and stored in $-80^{\circ} \mathrm{C}$. mRNA profiling by RNA-seq was performed. Unpaired t-tests with multivariate permutation correction were applied to identify differentially expressed genes (DEGs) between patients and $\mathrm{HC}$ for each disease and within diseases. Enrichment analysis, Gene ontology (GO) and Kyoto Enrichment of Genes and Genomes (KEGG) analysis were also performed. DEGs that allow to distinguish each disease from $\mathrm{HC}$ and between diseases. The top DEGs (axSpA $n=2$, RA $n=2, S L E n=3$ ) identified were confirmed by quantitative RT-PCR.

Results: For axSpA, genes involved in negative regulation of cytokines by JAK/STAT pathway and in osteoblast differentiation through STAT3 pathway, were confirmed. In SLE, genes involved in trap for immune complexes in peripheral blood and involved in nucleosome regulation, were also confirmed. Regarding RA, no genes were confirmed. Conclusion: Our work provides new insights into IRD pathogenesis, and discloses new biomarkers, which may be useful as either predictive biomarkers for diagnosis or therapeutic targets to improve IRD approach.Further validation are needed in different cohorts

\section{References:}

[1] Monti, S. et al. (2015) 'Rheumatoid arthritis treatment: The earlier the better to prevent joint damage,' RMD Open, 1(Suppl 1), pp. 1-5. doi: 10.1136/ rmdopen-2015-000057.

[2] Oglesby, A. et al. (2014) 'Impact of early versus late systemic lupus erythematosus diagnosis on clinical and economic outcomes., Applied health economics and health policy, 12(2), pp. 179-90. doi: 10.1007/ s40258-014-0085-x.

Acknowledgments: To all patients and healthy controls who participated in the study

Disclosure of Interests: Atlas Mashayekhi Sardoo: None declared, Paul Leo: None declared, Mariana Santos: None declared, Tiago Costa: None declared, Sergio Fernandes Almeida: None declared, Sara Maia: None declared, Vladimir Benes: None declared, Mattew Brown Speakers bureau: MSD, Pfizer, Novartis, Jaime Branco Speakers bureau: Vitoria, Fernando Pimentel dos Santos Speakers bureau: Novartis, Pfizer, Biogen, Vitoria,

DOI: 10.1136/annrheumdis-2020-eular.5456

\section{AB0016 ASSOCIATION OF PTPN22 GENETIC VARIANTS WITH DISEASE SUSCEPTIBILITY AND CLINICAL VARIABLES IN PRIMARY SJÖGREN SYNDROME}

P. A. Menchaca Tapia ${ }^{1}$, E. Oregón Romero ${ }^{1}$, D. C. Salazar Camarena ${ }^{2}$, M. Marin Rosales $^{1,3}$, J. F. Muñoz Valle ${ }^{1}$, C. A. Palafox Sánchez ${ }^{1} .{ }^{1}$ CUCS, Universidad de Guadalajara, Instituto de Investigación en Ciencias Biomédicas, Guadalajara, Jalisco, Mexico; ${ }^{2}$ CUCS, Universidad de Guadalajara, Laboratorio de Biomateriales, Guadalajara, Jalisco, Mexico; ${ }^{3}$ Hospital General de Occidente, Reumatología, Zapopan, Jalisco, Mexico

Background: Primary Sjögren's syndrome (pSS) is a systemic autoimmune disease characterized by dysfunction of exocrine glands secondary to lymphocytic infiltration. Lymphoid tyrosine phosphatase (LYP) regulates T and B lymphocyte activation. PTPN22 gene encodes LYP; multiple polymorphic variants have been described as genetic risk factor of autoimmune diseases.

Objectives: The aim was to analyze the PTPN22 rs2488457G $>C$, rs33996649G $>A$, and rs2476601C $>T$ genetic variants relationship with the development risk of pSS in the western Mexico population.

Methods: One hundred and eighty healthy subjects (HS) and $150 \mathrm{pSS}$ patients, classified according to EULAR 2016 criteria, were included. The genetic variants and mRNA expression were determined through PCR-RFLP and qPCR assays. 
Results: The frequency of heterozygote rs33996649GA genotype was higher in pSS patients than HS [OR=3.143 (1-10.234), $p=0.046]$, and also, rs33996649GA genotype was associated with high SSDAI score $(p=0.01)$. The pSS patients showed 44-fold more mRNA expression in comparison with HS $(p=0.002)$, and mRNA expression correlates with SSDAI $\left(r^{2}=0.512\right.$, $\mathrm{p}=0.006)$.

Conclusion: The rs33996649G>A genetic variant of the PTPN22 gene is associated with increased development risk of pSS in the western Mexican population. The expression mRNA correlates with disease activity in pSS.

References:

[1] Brito-Zerón, P., Baldini, C., Bootsma, H., Bowman, S. J., Jonsson, R., Mariette, X., Ramos-Casals, M. (2016). Sjögren syndrome. Nature Reviews Disease Primers, 2(July), 1-20. https://doi.org/10.1038/nrdp.2016.47

[2] Stanford, S. M., \& Bottini, N. (2014). PTPN22: The archetypal non-HLA autoimmunity gene.Nature Reviews Rheumatology, 10(10), 602-611.https://doi. org/10.1038/nrrheum.2014.109

[3] Chen, Z., Zhang, H., Xia, B., Wang, P., Jiang, T., Song, M., \& Wu, J. (2013). Association of PTPN22 gene (rs2488457) polymorphism with ulcerative colitis and high levels of PTPN22 mRNA in ulcerative colitis. International Journal of Colorectal Disease, 28(10), 1351-1358. https://doi.org/10.1007/ s00384-013-1671-3

[4] Machado-Contreras, J. R., Muñoz-Valle, J. F., Cruz, A., Salazar-Camarena, D. C., Marín- Rosales, M., \& Palafox-Sánchez, C. A. (2016b). Distribution of PTPN22 polymorphismsin SLE from western Mexico: correlation with mRNA expression and disease activity. Clinical and Experimental Medicine, 16(3), 399-406. https://doi.org/10.1007/s10238-015-0359-0

Disclosure of Interests: None declared

DOI: 10.1136/annrheumdis-2020-eular.2173

\begin{tabular}{l|l}
\hline AB0017 & CONSTANT GENETIC MARKER IL1B T-31C IS \\
ASSOCIATED WITH ANAMNESIS OF BIOLOGICAL \\
DRUGS TREATMENT IN RHEUMATOID ARTHRITIS
\end{tabular}

V. Omelchenko ${ }^{1}$, E. Letyagina ${ }^{1}$, Y. Kurochkina ${ }^{1}$, A. Akimova ${ }^{1}$, A. Shevchenko ${ }^{1}$ M. Korolev ${ }^{1}{ }^{1}$ RICEL - Branch of IC\&G SB RAS, Novosibirsk, Russian Federation

Background: Rheumatoid arthritis (RA) is chronic progressive joint disease with erosions formation. Timely and effectiveness treatment is important due to quickly structural damage and progressive losing of active motion. Synthetic DMARDs didn't have a sufficient effect. Using biological drugs seemed like a panacea, but according to investigations at least 30-40\% RA-patients lost treatment efficiency. Biological drugs act through immune cascade, that's why mutation in regulatory region of cytokine genes may partly determine treatment failure.

Objectives: The objective of our study was to analyze the frequency of IL1T-31C single nucleotide polymorphism in patient with rheumatoid arthritis and its association with biological drugs prescribing.

Methods: One hundred two Caucasian RA-patients (age - 56 yrs [45; 61]; DAS28 4.7 [3.8; 5.9]) were enrolled in our study. All of them had American College of Rheumatology (ACR)-defined RA (1987 classification criteria) and gave written inform consent. Single nucleotide polymorphisms IL1B T-31C (rs1143627), IL4 C-590T (rs2243250), IL10 C-592A (rs1800872), IL10 A-1082G (rs1800896) were determined by restriction fragment length polymorphism. Descriptive statistics, Chi-squared test were used for data analysis. Results are presented as median and 25th/75th percentiles (Me [25th percentile; 75th percentile]).

Results: The most of SNPs analyzed had corresponded to the Hardy Weinberg equilibrium (HWE). The only exception was IL1B T-31C - the frequencies were differed statistically significant from HWE $(p=0,03)$. Forty seven $(46.1 \%)$ patients were treatment with biological drugs. Homozygotes IL $1 \mathrm{~b}-31 \mathrm{CC}$ were founded more frequently beside patients with biological treatment compare with other group (13 from $47(27,7 \%)$ vs. 6 from $52(11.5 \%), p=0,042)$. Other SNPs didn't demonstrate any associations.

Conclusion: Single nucleotide polymorphism IL1B T-31C (rs1143627) may be used for prognosis of basic anti-inflammatory therapy inefficiency and the needing for prescribing biological therapy.

Disclosure of Interests: None declared

DOI: 10.1136/annrheumdis-2020-eular.2404

\section{AB0018 $\quad$ TNFA RS1800629 POLYMORPHISM: WHAT ABOUT ITS ASSOCIATION WITH CLINICAL MANIFESTATIONS AND ANTI-TNFA THERAPY? DATA FROM A SERIES OF ITALIAN PATIENTS WITH BEHÇET SYNDROME}

M. C. Padula ${ }^{1,2}$, P. Leccese ${ }^{1}$, N. Lascaro ${ }^{1}$, G. G. Sorrento ${ }^{2}$, R. P. Radice ${ }^{2}$, A. R. Limongi ${ }^{2}$, T. Carbone ${ }^{1}$, A. Padula ${ }^{1}$, G. Martelli ${ }^{2}$, S. D'angelo ${ }^{1}{ }^{1}$ Rheumatology Institute of Lucania (IReL), San Carlo Hospital of Potenza, Potenza, Italy;

${ }^{2}$ University of Basilicata, Potenza, Italy
Background: Tumor Necrosis Factor-alpha (TNF-a) is a pleiotropic cytokine with a critical role in the pathogenesis of Behçet syndrome (BS). Anti-TNFa therapy is useful for patients with refractory, severe BS, in particular for ocular, central nervous system, and gastrointestinal manifestations. However, although biological treatment with anti-TNF-a agents are effective in BS, not all patients are definite responders. Non-responders patterns could be due to: alternative non-TNFa related pathway of inflammation; anti-drug antibodies presence or development; polymorphic alleles of $T N F a$ gene. TNFa rs1800629 (-308G $>A)$ is a drug-response single nucleotide polymorphism (SNP) located within the gene promoter. Poor and conflicting data are currently available about the association of this polymorphism and clinical manifestations of BS, as well as about the responsivness to the TNFa blockers in BS patients [1-3].

Objectives: Aims of this study were to investigate in a cohort of Italian patients with BS the frequency of rs1800629 genotypes and its association with clinical features and anti-TNFa therapy response.

Methods: Consecutive patients with BS were recruited. Patients demographic and clinical data were collected by medical records and analyzed. Home-made specific primer pairs were used for rs 1800629 coverage. gDNA was isolated and amplified using PCR. Good-quality amplicons were sequenced (Sanger method) In silico analysis was downstream performed using specific software for querysubject similarity analysis.

Results: 130 BS patients (64M:66F; mean age: $45.8 \pm 12.3$ years) were included in the study. Patients predominant lesions were oral aphtosis $(100 \%)$, eye involvement $(86.2 \%)$, skin lesions $(72.3 \%)$ and genital ulcers (57.7\%). TNFa rs 1800629 wild-type GG genotype was found in 106/130 BS patients $(81.5 \%)$; the heterozygous genotype (GA) was identified in $24 / 130$ patients $(18.5 \%)$. No statistically significant differences were found in genotypes frequencies when the patients were stratified for presence and absence of each clinical manifestation $(p>0.05)$, while statistical significant differences were found when the patients were compared for therapy (antiTNFa drugs) response. In detail, $73 / 130$ patients $(56.2 \%)$ were treated with anti-TNFa agents. We found $16 / 73(21.9 \%)$ non-responders patients (NRP). In NRP group, we identified $9 / 16$ patients (56.3\%) with GG genotype and $7 / 16$ $(43.7 \%)$ with GA genotype, while $8 / 57(14.0 \%)$ responder patients showed GA genotype and $49 / 57$ responder patients (86.0\%) showed GG genotype $(p=0.0093$; OR: 0.21, Cl: 0.06-0.729).

Conclusion: Here we described a low frequency of TNFa rs1800629 SNPcontaining allele and the lack of association between SNP and BS clinica hallmark, as previously reported in literature [1-4]. We also found higher percentage of GG genotype in case of therapy response than GA genotype. The SNP is a promoter polymorphism that could affect the auto-inflammatory response and the therapy responsivness, as suggested by our preliminary data of pharmacogenomics. Analyses of a larger cohort of patients are need to confirm the study findings and to explain the SNP role as outcome predictor.

\section{References:}

[1] Touma Z et al. (2010). Arch Med Res 41(2):142-6;

[2] Vallet $\mathrm{H}$ et al. (2015). J Autoimmun 62:67-74

[3] Zhang M et al. (2013). Mol Vis 19:1913-24.

[4] Ateş A et al. (2006). Rheumatol Int 26(4):348-53.

Disclosure of Interests: Maria Carmela Padula: None declared, Pietro Leccese: None declared, Nancy Lascaro: None declared, Giusi Gaia Sorrento: None declared, Rosa Paola Radice: None declared, Antonina Rita Limongi: None declared, Teresa Carbone: None declared, Angela Padula: None declared, Giuseppe Martelli: None declared, Salvatore D’Angelo Consultant of: AbbVie, Biogen, BMS, Celgene, Eli Lilly, MSD, Novartis, and UCB, Speakers bureau: AbbVie, BMS, Celgene, Eli Lilly, Novartis, Pfizer and Sanofi

DOI: 10.1136/annrheumdis-2020-eular.2295

\section{AB0019 \\ GENETIC POLYMORPHISM OF THE INFLAMMATORY MARKER SAA1 RS12218 (-13 T/C) IS ASSOCIATED WITH AN APTITUDE TO CLINICAL PHENOTYPES OF JUVENILE IDIOPATHIC ARTHRITIS}

E. Fedorov ${ }^{1}$, S. Salugina ${ }^{2}$, M. Krylov ${ }^{3}$, I. Guseva ${ }^{3}$, E. Samarkina ${ }^{3} .{ }^{1}$ V.A Nasonova Research Institute of Rheumatology, Pediatric, Moscow, Russian Federation; ${ }^{2}$ V.A. Nasonova Research Institute of Rheumatology, Pediatric, Moscow, Russian Federation; ${ }^{3}$ V.A. Nasonova Research Institute of Rheumatology, Immunology and Molecular Biology of Rheumatic Diseases, Moscow, Russian Federation

Background: Juvenile idiopathic arthritis (JIA) is one of the most widely-spread immuno-inflammatory diseases of an unknown etiology, the leading manifestation of which is chronic joint inflammation, occuring in children under the age of 16. The disease is a complex of chronic arthropathies with various phenotypic manifestations. 